\title{
Intraradicular rehabilitation of a necrotic, immature tooth using MTA, a fiber post and composite resin - A case report
}

SADJ July 2021, Vol. 76 No. 6 p358 - p362

D Naicker ${ }^{1}$, S Tootla ${ }^{2}$

\begin{abstract}
Endodontic treatment of necrotic, immature teeth with open apices can present challenges to debridement, disinfection, and optimal obturation. These teeth may have widely flared canals and thin radicular dentinal walls that are susceptible to fracture. Management of the open apex can be performed using a mineral trioxide aggregate (MTA) apical plug. To ensure a better prognosis in such structurally compromised teeth, internal radicular reinforcement using fiber posts and a self-adhesive cement has been suggested. The present case report illustrates the management of a necrotic, immature maxillary right central incisor in a 10-year-old patient using the MTA apical barrier technique and canal reinforcement using a fiber post.
\end{abstract}

\section{Keywords}

Apexification, calcium hydroxide, fiber post, mineral trioxide aggregate.

\section{INTRODUCTION}

Studies on the prevalence of dental trauma have shown $20 \%-30 \%$ of children sustain traumatic dental injury to their permanent dentition. ${ }^{1}$ The majority of these incidents occur before root formation is complete and may result in pulpal inflammation or necrosis. With the loss of vitality and subsequent arrested root development, the open and sometimes divergent apical morphology, along with thin and fragile dentinal walls, represents both an endodontic and restorative challenge. It is imperative that these structurally compromised teeth are preserved in the young

\section{Author affiliations:}

1. Deon Naicker: BDS(Wits), Postgrad Dip.Clin Dent (UWC), MRACDS (Endo), FRACDS, D.Clin. Dent. (Endo)(Adel), Adelaide Health and Medical Sciences building, Corner of North Terrace and George Street, Adelaide, Australia.

ORCID Number: 0000-0002-7661-1129

2. Saidah Tootla: $B C H D, M S c D e n t$, Department of Paediatric and Restorative Dentistry, School of Oral Health Sciences, Faculty of Health Sciences, University of the Witwatersrand, Johannesburg, South Africa.

Corresponding author: Deon Naicker

Adelaide Health and Medical Sciences building, Corner of North Terrace and George Street, Adelaide, South Australia, 5000, Australia.

Email: drdeonnaicker@yahoo.com

Author contributions:

1. Deon Naicker: Treating Enododontist and write up - $75 \%$

2. Saidah Tootla: Reviewer and revision of write up $-25 \%$ patient, as alternative treatment options such as implantsupported restorations or fixed prostheses require completion of craniofacial growth for acceptable outcomes. ${ }^{2}$ Although regenerative procedures are the current protocol, clinical translation is relatively new in its inception and requires further research. Therefore, we chose a current and clinically reliable procedure for the treatment of this presenting case.

Thus, the purpose of this case report is to discuss the intricacies of treatment of a fractured, necrotic, immature maxillary central incisor using the MTA apical barrier technique and fiber post placement.

\section{CASE REPORT}

A 10-year-old male patient with non-contributory medical history was referred for evaluation and treatment of his fractured immature maxillary right central incisor. He had suffered a traumatic sporting injury with loss of the coronal fragment of the tooth and subsequent loss of vitality 12 months prior. Therapeutic dressings of calcium hydroxide had been applied by his general dentist at the local community clinic to induce apical closure. However, patient compliance regarding regular attendance had been poor.

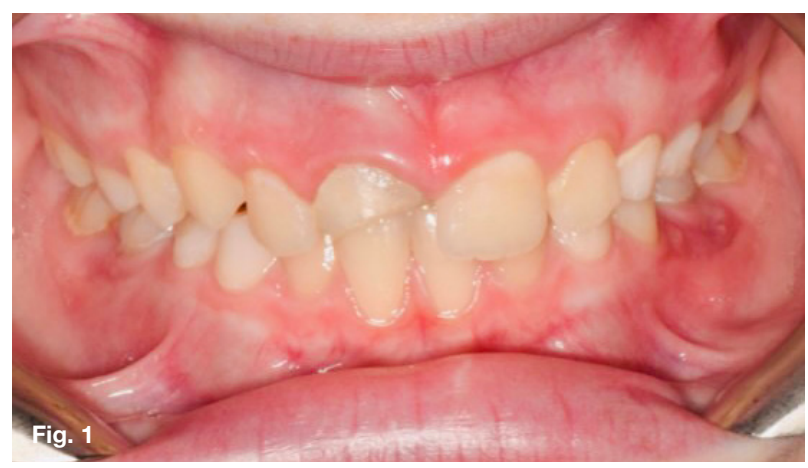

Clinical examination revealed a complicated crown fracture of the maxillary right central incisor with evidence of an interim glass ionomer restoration over the access cavity (Fig. 1). Periapical radiographs demonstrated an incompletely formed root apex with normal apical tissues. There was evidence of an intracanal calcium hydroxide dressing. A root development stage 2 to 3 was establish$\mathrm{ed}^{3}$ (Fig. 2). 
Due to a history of poor compliance in attending regular appointments, the mineral trioxide aggregate (MTA) apical barrier technique (ProRoot MTA; Dentsply Tulsa Dental, Johnson City, TN, USA) was chosen as the most viable treatment option. Consent from both the child and attendant parent was obtained with a detailed explanation of treatment rationale. On the first visit, root canal treatment was initiated. Local anaesthetic infiltration was administered using 2\% lidocaine with 1:80 000 epinephrine (Lignospan Special, Septodont, Saint-Maur-desFosses, France) over the maxillary right central incisor.
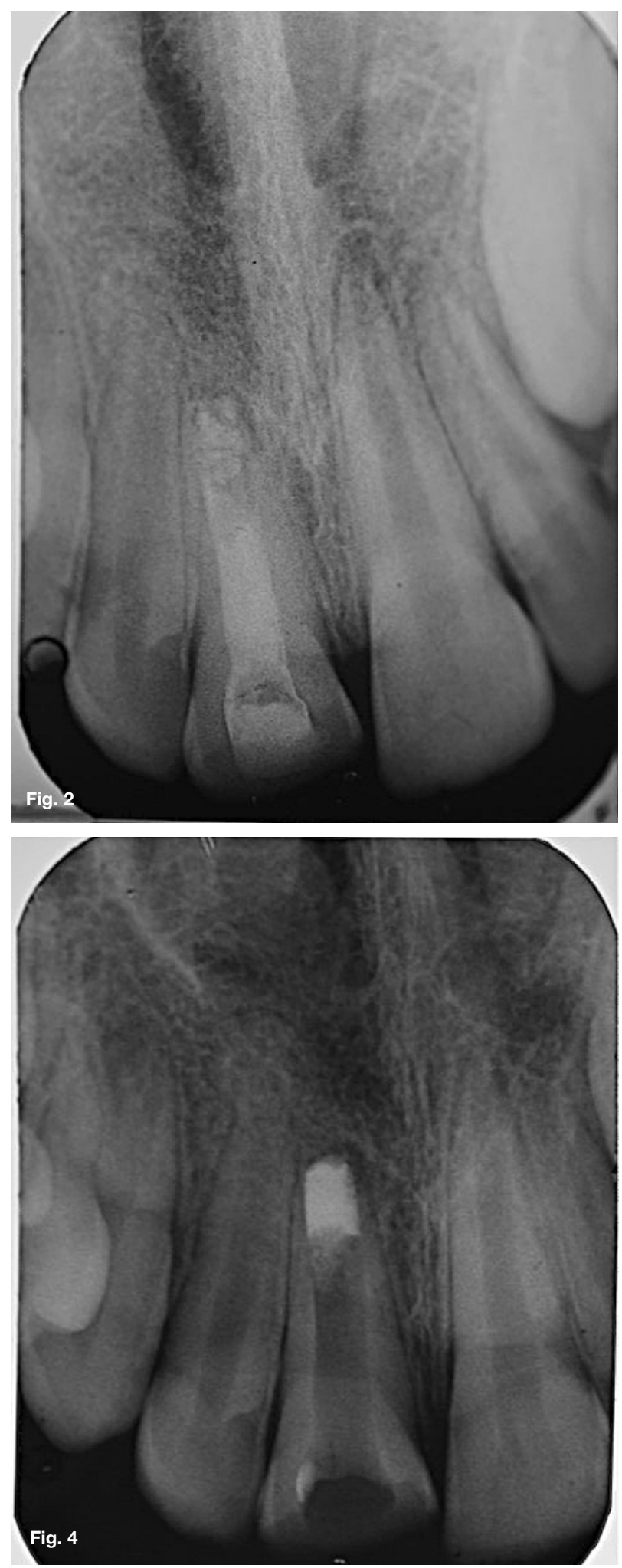

Following rubber dam application, access to the pulp chamber was gained. Working length was then established using an apex locator (Root ZX) (J Morita MFG Corp., Kyoto, Japan), with accuracy further confirmed with a periapical radiograph (Fig. 3).

Cleaning and shaping was carefully performed using large stainless-steel K-files (Dentsply Maillefer, Baillagues, Switzerland), supplemented with copious irrigation using 1\% sodium hypochlorite (NaOCl) (Endosure 1\% Hypochlor, Dentalife, Victoria, Australia). After drying with sterile, ab-
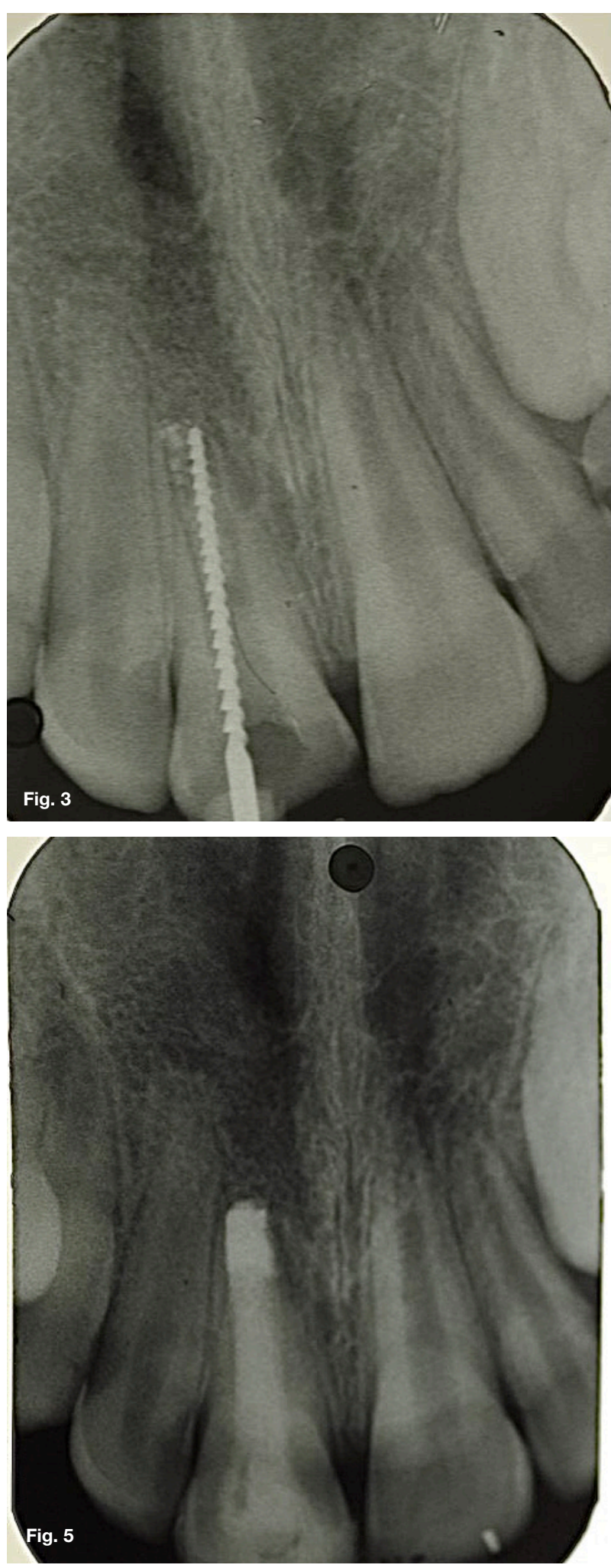
sorbent paper points, the root canal system was dressed with calcium hydroxide paste $\left(\mathrm{Ca}(\mathrm{OH})_{2}\right)(\mathrm{Calxyl} \mathrm{OCO}$ PRÄPARATE $® \mathrm{GMBH}$, Dirmstein, Germany) using a lentulo spiral. A temporary coronal restoration was established with a sterile cotton pellet, Cavit (ESPE, Seefeld, Germany) and Fuji IX glass ionomer cement (GC, IL, USA). The patient was scheduled for a second visit after six weeks.

The tooth was asymptomatic during the entire post-operative period, and the provisional restoration was still intact at the second visit. Local anaesthesia was accomplished with Lignospan Special. After isolation with rubber dam, the provisional restoration was removed from the access cavity.

A copious amount of $1 \% \mathrm{NaOCl}$ was ultrasonically activated to remove the $\mathrm{Ca}(\mathrm{OH})_{2}$ paste from the canal. Before MTA application, the canal was irrigated with 15\% ethylenediaminetetraacetic acid (EDTA) (Endosure EDTA 15\% Solution, Dentalife, Victoria, Australia) to remove the smear layer and again with $1 \% \mathrm{NaOCl}$. The root canal was then dried with sterile absorbent paper points. White ProRoot MTA was mixed with sterile water according to the manufacturer's instructions.

The application of an apical barrier of $4-5 \mathrm{~mm}$ of MTA was completed using a Lee block (San Francisco, USA) and Buchanan Pluggers (Sybron Endo, Orange, CA, USA). It was further compacted using indirect ultrasonic compaction. Thus, a $5 \mathrm{~mm}$ apical plug was obtained and a radiograph exposed to verify density and position of the MTA plug (Fig. 4). After application of MTA, a paper point moistened with sterile water was left in contact with the MTA plug and the access cavity sealed temporarily using Cavit and Fuji IX glass ionomer cement.

At the next visit 24 hours later, the provisional access cavity restoration was removed under rubber dam application. A Buchanan's plugger was then inserted to confirm the complete setting of the MTA apical plug. The root canal was then irrigated with $1 \% \mathrm{NaOCl}$, followed by saline and dried with paper points. A Rely-X Fiber Post (3M ESPE, Germany) was trimmed and cemented with Rely-X Unicem Self-Adhesive Universal Resin Cement (3M ESPE, Germany) - shade A2. No additional instrumentation was needed to accommodate the post due to the widely flared canal walls, thus preserving intraradicular dentine. Composite aesthetic restoration was completed using AdperTM ScotchbondTM Multi-purpose adhesive (3M ESPE, Germany) and a layered stratification technique incorporating Filtek Supreme XTE Universal Restorative Composite (3M ESPE, Germany) A2 body and A1 enamel shades. Soflex discs (3M ESPE, Germany) were used for aesthetic recontouring and polishing.

Occlusion was adjusted for centric and eccentric excursions. A final post-operative radiograph was taken (Fig. 5). The patient and his parents were satisfied with the aesthetic appearance of the restoration (Fig. 6). Use of a custom fitted mouthguard was advised for any contact sports to mitigate against any possible future fracture.

It was further reiterated that the treatment provided is to ensure preservation of the tooth till craniofacial growth is completed, hence due care is advised.

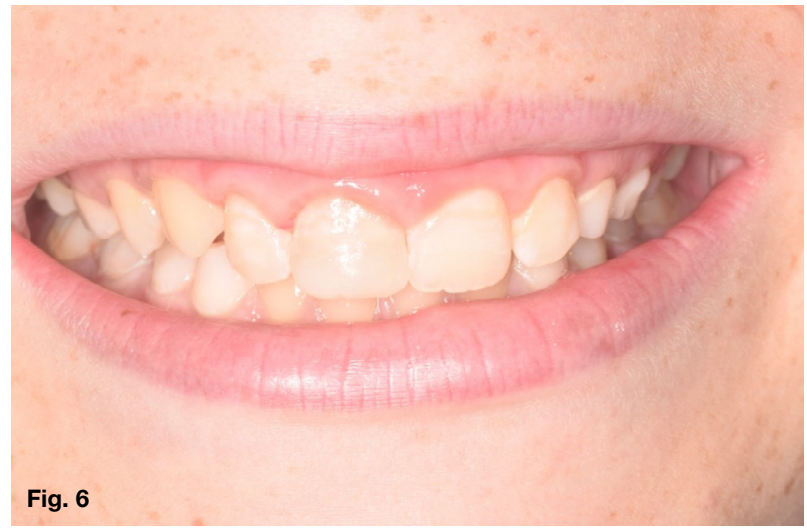

The patient was recalled after 12 months. He reported that no symptoms had occurred and no complications were noted. The restoration still appeared acceptable (Fig. 7). A periapical radiograph demonstrated that the fiber post and restoration remained satisfactory with normal periapical tissues (Fig. 8).
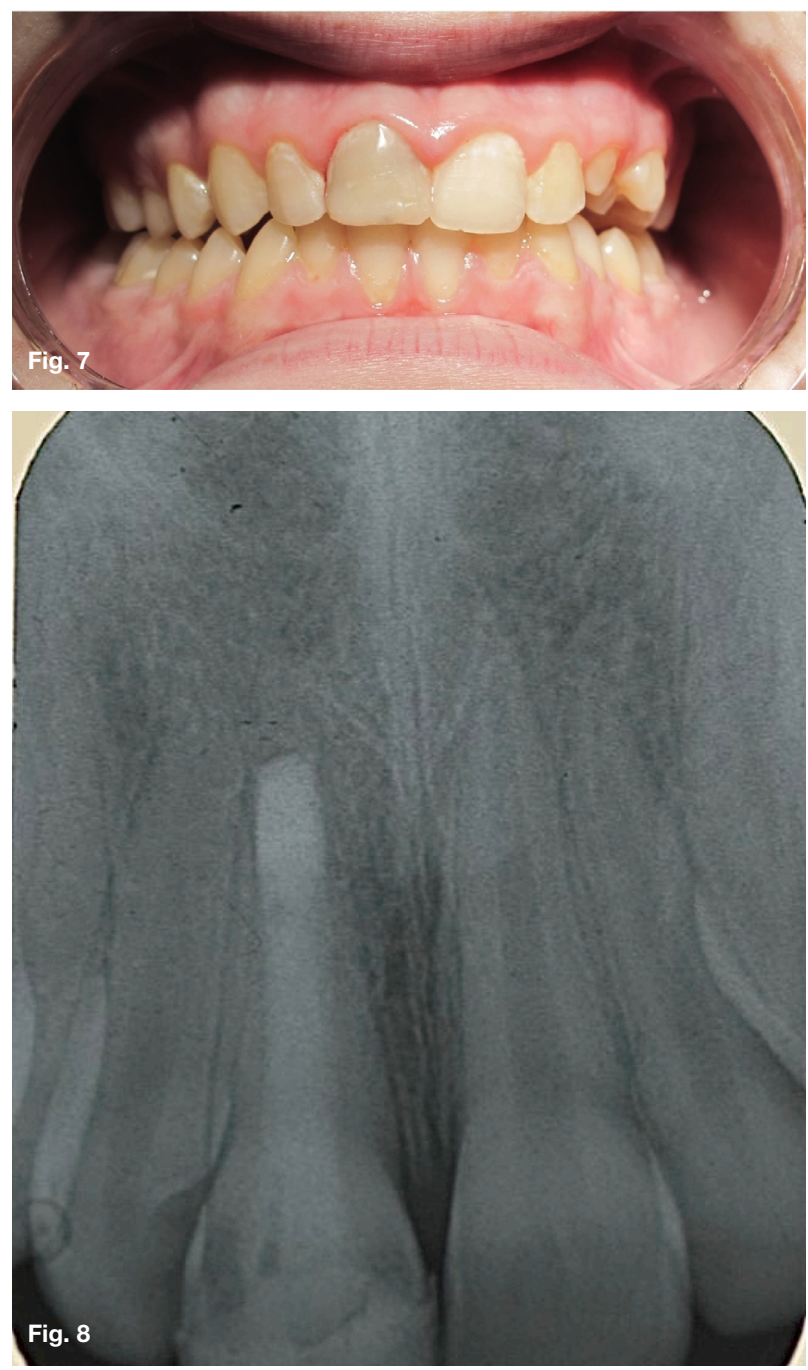

\section{DISCUSSION}

Apexification is defined as a method to induce a calcified barrier in a root with an open apex or the continued apical development of an incompletely formed root in immature teeth with necrotic pulps. ${ }^{4}$ Traditionally, the most commonly used material for apexification is calcium hydroxide. 
Success rates are reported to be in the mid $90 \%$ range. ${ }^{5}$ Disadvantages to this technique include the need for multiple appointments, extended treatment time, possible patient compliance issues and susceptibility to re-infection. ${ }^{6}$ There also exists the possibility of weakening of tooth structure ${ }^{7,8,9}$ with subsequent root fracture.

Considering these significant disadvantages, an alternative treatment to traditional apexification with calcium hydroxide may offer a better prognostic outcome. Studies have indicated MTA as an alternative to calcium hydroxide. ${ }^{10,11}$ The advantages of MTA include excellent biocompatibility, ${ }^{12}$ induction of hard tissue, ${ }^{11}$ and good sealing properties. ${ }^{13,14}$ Additional advantages include a shorter treatment time and development of a good apical seal. ${ }^{15,16}$

Despite these advantages, the root canal walls in these teeth remain thin, weak, and susceptible to fracture. Thus, restorative protocols able to reinforce the root architecture are important. ${ }^{17,18}$ It has been hypothesized that filling root canals with an adhesive material with a similar elastic modulus to dentine could improve the fracture resistance and stress distribution in immature teeth..$^{13,19}$ Materials which have a modulus of elasticity similar to dentine enable the equitable distribution of forces along the root canal walls. Several materials have been used in an attempt to reinforce teeth, with composite resin and fiber posts showing promise. ${ }^{20}$

Composite resin has the ability to bond to root dentine walls, increasing the strength of the roots. ${ }^{19}$ Unfortunately, it has relatively low strength under tensile stress. ${ }^{21}$ Studies have also shown that thermocycling might significantly reduce the flexural strength of composite. ${ }^{22,23,24}$ An alternative to increase fracture resistance would be the use of fiber posts. ${ }^{18,25-27}$ Fiber posts have a modulus of elasticity similar to dentine and can be adhesively bonded to dentine, decreasing the risk of restorative failure and supporting tensile stress more effectively. ${ }^{28,29}$ Fiber posts might also more evenly distribute forces along the root, reducing stress concentrations. . $^{25,26}$

Cementation procedures using self-adhesive resin cements are simpler than conventional bonding procedures used in root canals. Additionally, self- adhesive resin cements appear to have low shrinkage due to their viscoelastic properties. ${ }^{30}$ Polymerization shrinkage is also reduced by a lower volume of material as the fiber post occupies most of the space in the root canal. In this case, no additional intraradicular dentine removal was required to accommodate post cementation, further maintaining structural integrity of the tooth.

\section{CONCLUSION}

Management of a necrotic, immature, and structurally compromised tooth through an approach employing the use of the MTA apical barrier technique and reinforcement with a fiber post can be a simple and efficient procedure with excellent aesthetic and functional results.

\section{References}

1. Andersson L. Epidemiology of Traumatic Dental Injuries. J Endod. 2013; 39: S2-5.

2. Op Heij DG, Opdebeeck H, Steenberghe DV, Kokich VG, Belser U, Quirynen M. Facial development, continuous tooth eruption and mesial drift as compromising factors for implant placement. Int J Maxillofac Implants. 2006; 21: 867-78.

3. Moorrees CFA, Fanning EA, Hunt EE. Age variation of formation stages for ten permanent teeth. J Dent Res. 1963; 42: 1490-502.

4. American Association of Endodontists Glossary of endodontic terms. $9^{\text {th }}$ ed. Chicago: American Association of Endodontists. 2015. Accessed on 7 June 2017.

5. Cvek M. Prognosis of luxated non-vital maxillary incisors treated with calcium hydroxide and filled with gutta-percha: a retrospective clinical study. Endod Dent Traumatol. 1992; 8: 45-55.

6. Holden DT, Schwartz SA, Kirkpatrick TC, Schindler WG. Clinical Outcomes of Artificial Root-end Barriers with Mineral Trioxide Aggregate in Teeth with Immature Apices. J Endod. 2008; 34: 812-7.

7. Andreasen JO, Farik B, Munksgaard EC. Long-term calcium hydroxide as a root canal dressing may increase risk of root fracture. Dent Traumatol. 2002; 18: 13-7.

8. Rosenberg B, Murray PE, Namerow K. The effect of calcium hydroxide root filling on dentin fracture strength. Dent Traumatol. 2007; 23: 26-9.

9. Doyon GE, Dumsha T, von Fraunhofer JA. Fracture resistance of human root dentin exposed to intracanal calcium hydroxide. J Endod 2005; 12: 895-7.

10. Tittle K, Farley J, Linkhart T, Torabinejad M. Apical closure induction using bone growth factors and mineral trioxide aggregate. J Endod. 1996; 22: 198-203

11. Shabahang S, Torabinejad M, Boyne PP, Abedi H, McMillan P. A comparative study of root-end induction using osteogenic protein-1, calcium hydroxide, and mineral trioxide aggregate in dogs. J Endod. 1999; 25: 1-5.

12. Holland R, Filho JA, de Souza V, Nery MJ, Bernabe PF, Junior ED. Mineral trioxide aggregate repair of lateral root perforations. J Endod 2001; 27: 281-4.

13. Lawley GR, Schindler WG, Walker WA $3^{\text {rd }}$, Kolodrubetz D. Evaluation of ultrasonically placed MTA and fracture resistance with intracanal composite resin in a model of apexification. J Endod. 2004; 30: 167-72.

14. Torabinejad M, Watson TF, Pitt Ford TR. Sealing ability of a mineral trioxide aggregate when used as a root end filling material. J Endod. 1993; 19: 591-5.

15. Witherspoon DE, Small JC, Regan JD, Nunn M. Retrospective analysis of open apex teeth obturated with mineral trioxide aggregate. J Endod. 2008; 34: 1171-6.

16. Shabahang S, Torabinejad M. Treatment of teeth with open apices using mineral trioxide aggregate. Pract Periodontics Aesthet Dent. 2000; 12: 315-20.

17. Bortoluzzi EA, Souza EM, Reis JMSN, Esberard RM, Tanomaru-Filho M. Fracture strength of bovine incisors after intra-radicular treatment with MTA in an experimental immature tooth model. Int Endod J. 2007; 40: 684-91.

18. Dikbas, I, Tanalp, J, Koksal T, Yalnız A, Güngör T. Investigation of the effect of different prefabricated intracanal posts on fracture resistance of simulated immature teeth. Dent Traumatol. 2014; 30: 49-54.

19. Wilkinson KL, Beeson TJ, Kirkpatrick TC. Fracture resistance of simulated immature teeth filled with resilon, guttapercha, or composite. J Endod 2007; 33: 480-3.

20. Desai S, Chandler N. The restoration of permanent immature anterior teeth, root filled using MTA: A review. J Dent. 2009; 37: 652-7.

21. Cabrera E, Macorra JC, Microtensile. Bond strength distributions of three composite materials with different polymerization shrinkages bonded to dentin. J Adh Dent. 2011; 13: $39-48$. 
22. Butz F, Lennon AM, Heydecke G, Strub JR. Survival rate and fracture strength of endodontically treated maxillary incisors with moderate defects restored with different postand-core systems: an in vitro study. Int J Prosthodont. 2001; 14: 58-64.

23. Friedel W, Kern M. Fracture strength of teeth restored with all-ceramic posts and cores. Quintessence Int. 2006; 37: 289-95.

24. Janda R, Roulet JF, Latta M, Ruttermann S. The effects of thermocycling on the flexural strength and flexural modulus of modern resin-based filling materials. Dent Mater. 2006; 22: 1103-8.

25. Schmoldt SJ, Kirkpatrick TC, Rutledge RE, Yaccino JM. Reinforcement of simulated immature roots restored with composite resin, mineral trioxide aggregate, guttapercha, or a fiber post after thermocycling. J Endod. 2011; 37: 1390-3.

26. Brito-Júnior M, Pereira RD, Veríssimo $C$, et al. Fracture resistance and stress distribution of simulated immature teeth after apexification with mineral trioxide aggregate. Int Endod J. 2014; 47: 958-66.
27. Cauwels RGEC, Lassila LVJ, Martens LC, Vallittu PK, Verbeeck RMH. Fracture resistance of endodontically restored, weakened incisors. Dent Traumatol. 2014; 30: 348-55.

28. Prisco D, De Santis R, Mollica F, Ambrosio L, Rengo S, Nicolais L. Fiber post adhesion to resin luting cements in the restoration of endodontically-treated teeth. Operative Dent. 2003; 28: 515-21.

29. Santos-Filho PC, Castro CG, Silva GR, Campos RE, Soares CJ. Effects of post system and length on the strain and fracture resistance of root filled bovine teeth. Int Endod J. 2008; 41: 493-501.

30. Amaral M, Rippe MP, Bergoli CD, Monaco C, Valandro LF. Multi-step adhesive cementation versus one-step adhesive cementation: push-out bond strength between fiber post and root dentin before and after mechanical cycling. Gen Dent. 2011; 59: 185-91.

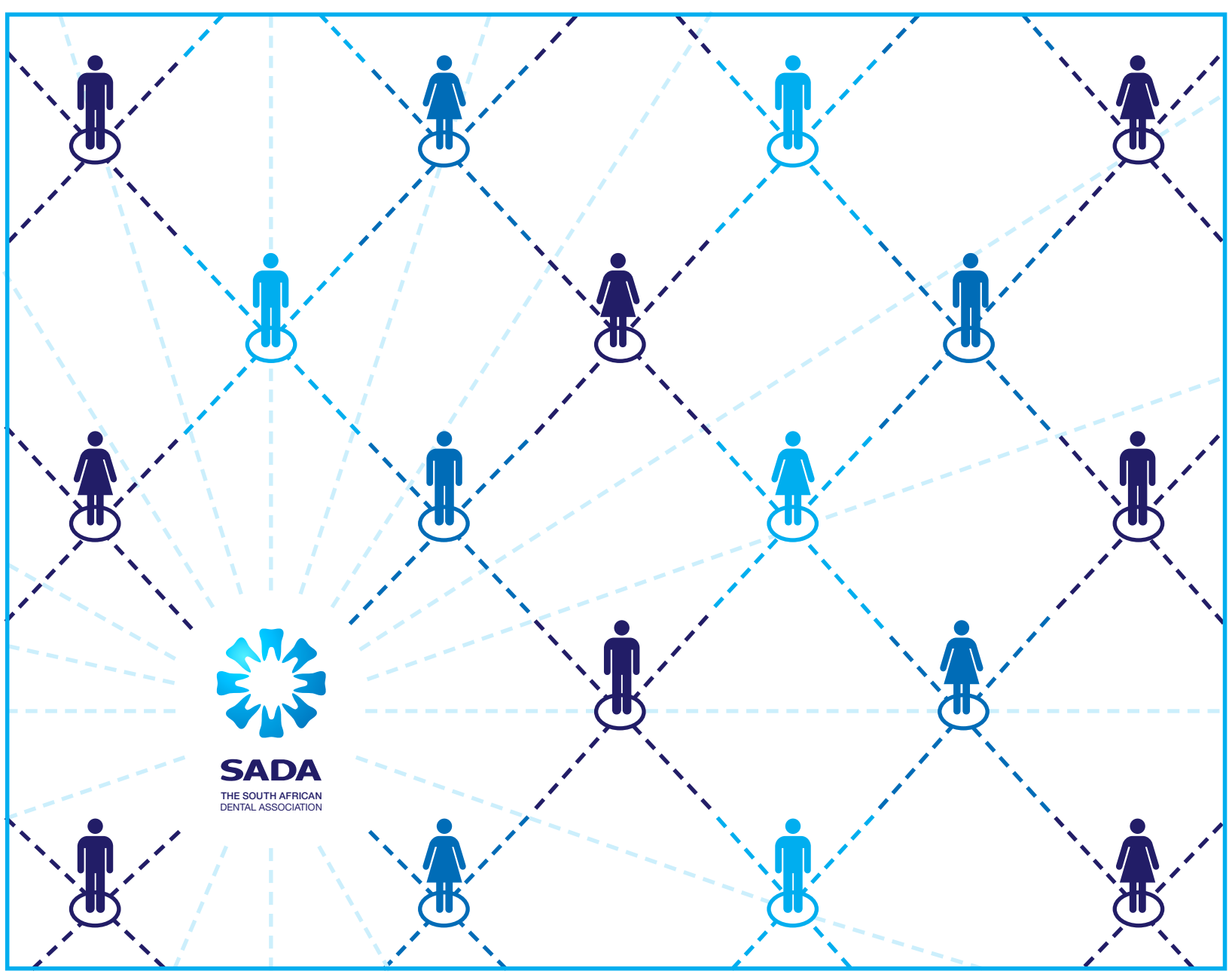

